Brazilian Journal
of Chemical
Engineering

\title{
PHENOLIC CONTENT, ANTIOXIDANT ACTIVITY AND ANTIAMYLOLYTIC ACTIVITY OF EXTRACTS OBTAINED FROM BIOPROCESSED PINEAPPLE AND GUAVA WASTES
}

\author{
B. A. Sousa ${ }^{1}$ and R. T. P. Correia ${ }^{1 *}$ \\ ${ }^{1}$ Laboratory of Food Technology, Department of Chemical Engineering, Phone: + (55) (84) 3215-3769, ext.231, \\ Fax: +(55) (84) 3215-3770, Universidade Federal do Rio Grande do Norte, 59072-970, Natal - RN, Brazil. \\ E-mail: roberta@eq.ufrn.br
}

(Submitted: April 5, 2011 ; Revised: September 12, 2011 ; Accepted: September 12, 2011)

\begin{abstract}
The relationship between phenolic content, antioxidant and antiamylolytic activities was investigated in Rhizopus oligosporus-mediated solid-state bioprocessing of pineapple and guava residues. Two different treatments of fruit residues mixed with soy flour $(5 \mathrm{~g}$ of soy flour and $5 \mathrm{~g}$ of fruit residue; $1 \mathrm{~g}$ of soy flour and $9 \mathrm{~g}$ of fruit residue) were inoculated and incubated at $22^{\circ} \mathrm{C}$. Phenol rich extracts (non-concentrated and concentrated 10-fold by boiling) from day 2 and 10 were tested for their ability to inhibit alpha-amylase. In order to correlate the enzymatic inhibition with phenolic-linked antioxidant activity of the extracts, samples were evaluated for total phenolic content and free radical scavenging. Alpha-amylase inhibition was observed for all extracts, concentrated or not, with values ranging from $10.91 \%$ to $100 \%$ (complete inhibition). A direct correlation between the total phenolic content or the free radical scavenging activity and alpha-amylase inhibition was not found, demonstrating that such an inhibition could be caused by the presence of specific compounds, phenolic or not, rather than by the actual concentration of overall fruit phenolics.

Keywords: Alpha-amylase inhibition; Solid substrate bioprocessing; Phenolics.
\end{abstract}

\section{INTRODUCTION}

Solid-state bioprocessing (SSB) deals with the utilization of water-insoluble material for microbial growth. It has been applied for the development of value-added products from a variety of nonexpensive materials, mainly agroindustrial wastes (Zheng and Shetty, 1999). It has also been identified as an efficient process for enriching plant substrates for beneficial food bioactive phytochemicals (Aguilera-Carbo et al., 2009; McCue and Shetty, 2005). According to Vattem and Shetty (2002), bioprocessing of pomace by solid state fermentation (SSF) using food grade fungi, such as Rhizopus oligosporus, commonly used for production of tempeh, provides unique strategies for improving nutraceutical properties and producing functional phenolic ingredients.

Brazil produces a large variety of colorful tropical fruits with exotic flavors. Guava (Psidium guajava L.), a globular shaped fruit, is widely grown in Brazil and is consumed fresh, as jam, guava juice or fruit pulp. Brazil is an important guava producer and it is also one of the greatest pineapple (Ananas cosmosus) producers in the world (FAO, 2010), which makes it a popular fruit found widely all over the country. According to Mantovani et al. (2004) and Rogério et al. (2007), after juice extraction, both fruits generate a heterogeneous mixture of peels, seeds and residual pulp which accounts for between $4-12 \%(\mathrm{w} / \mathrm{w})$ and $15-25 \%(\mathrm{w} / \mathrm{w})$ of guava and pineapple weight, respectively.

*To whom correspondence should be addressed 
Phenolic compounds are one of the possible products produced via SSB. These phytochemicals are a diversified group of secondary metabolites that are ubiquitous in the plant kingdom. According to many authors (Hounsome et al., 2008; Naczk and Shahidi, 2006; McCue and Shetty, 2005), phenolic compounds with health-promoting activity are found in dietary plants. Being so, fruits and vegetables represent remarkable sources of bioactive compounds that could play a role in preventing diseases caused as a result of oxidative processes, such as cardiovascular problems, auto-immune complications, type 2 diabetes and age-related dysfunctions (Morton et al., 2000; Kaur and Kapoor, 2001; Youdim and Joseph, 2001). It explains the great attention given to phenolic phytochemicals during the last decade and the large number of studies dealing with this subject.

Recent studies have shown that phenolic phytochemicals exert anti-diabetic activity through inhibition of carbohydrate-hydrolyzing enzymes, such as alpha-amylase and alpha-glucosidase. Natural alpha-amylase inhibitors offer an attractive approach to the management of postprandial hyperglycemia by decreasing glucose release from starch (Kim et al., 2005). Several findings (Apostolidis et al., 2007; Kwon et al., 2006) suggest that phenolic synergies may play a role in mediating amylase inhibition and therefore have the potential to contribute to the management of Type 2 diabetes. In addition, research results show that phenolic antioxidants have significant in vitro antiglycation properties (Lunceford and Gugliucci, 2005). Glycation, the non-enzymatic reaction between sugar dicarbonyls and protein, is one of the key mechanisms of diabetic complications due to hyperglycemia.

Here we investigate the relationship between phenolic content, antioxidant activity and antiamylase activity of selected bioprocessed phenolicenriched fruit waste extracts using the food grade fungus Rhizopus oligosporus. Furthermore, the effects of thermal processing and concentration on phenolic-linked functionality of bioprocessed fruit wastes extracts were also analyzed.

\section{MATERIAL AND METHODS}

\section{Material}

Commercial organic soy bean flour $(40 \%$ protein, Jasmine, Brazil) was used. The freshly pressed guava and pineapple processing wastes, consisting of residual pulp, peels and seeds containing approximately $80 \%$ moisture, were collected from a fruit pulp extractor unit (Natal, Brazil) and oven dried at $70^{\circ} \mathrm{C}$ for 8 hours. The dried fruit material was ground (guava $0.500 \mathrm{~mm}$, pineapple $0.707 \mathrm{~mm}$ ) and stored in a freezer $\left(-4^{\circ} \mathrm{C}\right)$ until use.

\section{Reagents}

Reagents 2,2-diphenyl-1-picrylhydrazyl (DPPH), Folin-Ciocalteau and the enzyme alpha-amylase (E.C.3.2.1.1) were purchased from Sigma Aldrich Chemicals (St Louis, MO). All other chemical and reagents were of analytical grade.

\section{Solid Substrate Cultivation}

Rhizopus oligosporus (CCT 3762) was obtained from Culture Collection André Tosello (SP, Brazil) and maintained on potato dextrose agar (PDA) at $4^{\circ} \mathrm{C}$. Culture was reactivated by transferring to fresh PDA plates and cultures at $22^{\circ} \mathrm{C}$ for $7-10$ days. Two treatments, one consisting of $5 \mathrm{~g}$ of soy flour and $5 \mathrm{~g}$ of guava or pineapple residue (P5 or G5), and another consisting of $1 \mathrm{~g}$ of soy flour and $9 \mathrm{~g}$ of guava or pineapple residue ( $\mathrm{P} 9$ or $\mathrm{G} 9$ ) were investigated using Erlenmeyer flasks $(250 \mathrm{~mL})$. Soy flour was used to compose the cultivation media and the 1:1 and 9:1 ratios of fruit to soy were selected to have distinct ranges of carbon to nitrogen ratios. The material was autoclaved at $121^{\circ} \mathrm{C}$ for 8 minutes in order to prevent excessive substrate burning and each flask, containing $10 \mathrm{~g}$ of the substrate, was inoculated with 10 squares (approx. $1 \mathrm{~cm}^{2}$ each) of activated $R$. oligosporus. Sterile distilled water was added to each flask (initial moisture 50\%), which was covered with gauze layers and incubated for 12 days at $22^{\circ} \mathrm{C}$. Each experiment was repeated 4 times and triplicate flasks were taken at day 2 and day 10, which were analyzed in triplicate $(n=36)$. These extracts were selected as early and late stages of SSB, respectively, for further studies on alpha-amylase inhibition.

After growth, $100 \mathrm{ml}$ of distilled water were added to each fungus-residue flask and the culture was homogenized in a Waring Blender for 1 minute, followed by vacuum filtration through Whatman no. 1 filter paper. The filtered extracts were used as the nonconcentrated samples. Concentrated extracts were obtained by boiling the filtered extracts on a hot plate at $100^{\circ} \mathrm{C}$ until the volumes had decreased 10 -fold.

\section{Analytical Methods}

The total phenolic content (TPC) and DPPH assay of extracts obtained from days 2 and 10 were 
measured according to Correia et al. (2004): For the TPC determination, $1 \mathrm{~mL}$ of the supernatant was mixed with $1 \mathrm{~mL}$ of $95 \%$ ethanol, $5 \mathrm{~mL}$ of distilled water and $0.5 \mathrm{~mL}$ of $50 \%(\mathrm{v} / \mathrm{v})$ Folin-Ciocalteau reagent and immediately vortexed. After 5 minutes, $1 \mathrm{~mL}$ of $5 \% \mathrm{Na}_{2} \mathrm{CO}_{3}$ was added and the solution allowed to stand for 60 minutes in the dark. The absorbance of the samples was measured at $725 \mathrm{~nm}$ against a $95 \%$ ethanol blank and results expressed as micrograms of gallic acid per gram of fresh weight ( $\mu \mathrm{g} \quad \mathrm{GAE} / \mathrm{g} \quad \mathrm{FW}$ ). A calibration curve was constructed using gallic acid as standard.

For the DPPH assay, one (1) $\mathrm{mL}$ of $1 \mathrm{mM} \mathrm{DPPH}$ radical solution in $95 \%$ ethanol was added to $1 \mathrm{~mL}$ of extract. The samples were centrifuged at $13,500 \mathrm{rpm}$ for 5 minutes at $28^{\circ} \mathrm{C}$ and their absorbance measured at $517 \mathrm{~nm}$ against a $95 \%$ ethanol blank. The antioxidant activity was expressed as percent (\%) DPPH scavenging calculated as (control absorbance - extract absorbance) / (control absorbance) x 100.

For antiamylolytic activity, concentrated and nonconcentrated phenolic-enriched extracts $(800 \mu \mathrm{L})$ were added to $200 \mu \mathrm{L}$ of porcine pancreatic alpha-amylase (PPA, E.C.3.2.1.1) solution equivalent to $1000 \mathrm{U}$ in 20 $\mathrm{mM}$ sodium phosphate buffer, $\mathrm{pH}$ 6.9. An aliquot of $100 \mu \mathrm{L}$ of this solution (equivalent to $40 \mu \mathrm{g}$ phenolics $1100 \mathrm{U}$ PPA) was added to sterile paper disks (Whatman AA discs 2017-013-B, England, $13 \mathrm{~mm}$ diameter) placed in Petri plates containing medium that consisted of $5 \mathrm{~g}$ of agar plus $5 \mathrm{~g}$ of starch in 500 $\mathrm{mL}$ of distilled water. Sealed plates were allowed to stand for 3 days at $28^{\circ} \mathrm{C} .5 \mathrm{~mL}$ of iodine stain solution was added, the excess iodine stain was drained and the diameter of the clear zone was measured. Control samples were performed by adding only the PPA solution to the paper disc. Results were reported as percentage of amylase inhibition and calculated as (diameter of the control-diameter of samples)/ (diameter of the control) x 100. Experiments were run in triplicate and the average values and standard deviations are reported.

\section{RESULTS AND DISCUSSION}

\section{Total Phenolic Content (TPC) and DPPH Inhibition of Concentrated and Non-Concentrated Samples}

The data reveal that SSB is especially efficient in increasing the total phenolic content of the G5 group (Table 1). After 10 days of growth, the G5 bioprocessed waste reached $1734 \mu \mathrm{gGAE} / \mathrm{g} \mathrm{FW}$, which is nearly 2.3-fold its initial concentration
$(769.5 \pm 3.4 \mu \mathrm{g}$ GAE/g FW). P5 samples at day 10 also exhibit a significant increase in their phenolic content $(2036.0 \mu \mathrm{gGAE} / \mathrm{g} \mathrm{FW}), 70 \%$ higher than their initial content (1383.7 $\mu \mathrm{gGAE} / \mathrm{g}$ FW). However, for the G9 and P9 treatments, only a slight increase in phenolic content was observed.

High antioxidant activity levels were observed for G9 and P9 non-concentrated samples during early and late stages of growth, while antioxidant activity of the G5 and P5 groups showed a significant drop after 10 days of bioprocessing.

Previously, Correia et al. (2004) had observed the same pattern for pineapple residues. The authors hypothesized that this marked difference in TPC increase between groups 5 and groups 9 may be due to the higher $\mathrm{C}: \mathrm{N}$ ratio of the G5/P5 treatments, where a higher soy flour content was used. For the G9/P9 treatment, nutritional limitations may lead to little TPC increase and maintenance of high antioxidant capacity until the end of the growth.

There is no evidence of a direct relationship between TPC and antioxidant activity measured by the DPPH method. It is suggested that the decisive factor to explain the antioxidant activity could be the phenolic composition of each extract and not simply the TPC. The hydrolysis of the fruit residues due to fungal enzymes should generate a complex mixture of compounds and the bioactive substances present in this material could interfere in the antioxidant action.

This hypothesis is supported by Randhir and Shetty (2007), who showed that the antioxidant activity of bioprocessed mung bean extracts correlated with the TPC only during certain stages of growth. This result can be explained by the fact that the antioxidant activity of these extracts depends on qualitative aspects and not just the total phenolic content.

Zheng and Wang (2003) also observed that the type of phenolic present could exert a crucial effect on its antioxidant activity. These authors showed that the contribution of individual phenolics to the total antioxidant capacity is dependent on their structure and content in blueberries, cranberries, chokeberries and lingonberries. For example, an increase in the number of phenolic hydroxyl groups and the presence of a primary alcohol are pointed out by Torres de Pinedo et al. (2007) as the main structural factors that help to increase the antioxidant capacity. The authors also noted that a small effect is observed when a longer alkyl chain is attached to the phenyl ring, which seems to help stabilize the radicals formed during the oxidation process. According to Bocco et al. (1998), it is also possible that non-phenolic substances could contribute for the antioxidant activity. 
Table 1: TPC and DPPH inhibition results for guava (G9, G5) and pineapple (P9, P5) concentrated and non-concentrated phenolic extracts after 2 and 10 days of growth.

\begin{tabular}{|c|c|c|c|c|c|}
\hline \multirow[b]{2}{*}{ Treatments } & \multirow[b]{2}{*}{ Days } & \multicolumn{2}{|c|}{ Non-concentrated (NC) } & \multicolumn{2}{|c|}{ Concentrated (C) } \\
\hline & & $\begin{array}{c}\text { TPC, } \\
\mu \mathrm{g} / \mathrm{g} \text { FW }\end{array}$ & $\begin{array}{c}\text { DPPH, } \\
\% \text { inhibition }\end{array}$ & $\begin{array}{c}\text { TPC, } \\
\mu \mathrm{g} / \mathrm{g} \text { FW }\end{array}$ & $\begin{array}{c}\text { DPPH, } \\
\% \text { inhibition }\end{array}$ \\
\hline \multirow{2}{*}{ G9 } & 2 & $\begin{array}{r}866.0 \\
(8.9)\end{array}$ & $\begin{array}{l}94.14 \\
(1.50)\end{array}$ & $20158.2(493.1)$ & $\begin{array}{l}92.75 \\
(1.25)\end{array}$ \\
\hline & 10 & $\begin{array}{r}999.6 \\
(2.3)\end{array}$ & $\begin{array}{l}92.58 \\
(1.14)\end{array}$ & $18541.8(312.8)$ & $\begin{array}{r}86.77 \\
(0.88)\end{array}$ \\
\hline \multirow{2}{*}{ G5 } & 2 & $\begin{array}{r}842.0 \\
(7.0)\end{array}$ & $\begin{array}{l}92.77 \\
(2.80)\end{array}$ & $19047.6(152.7)$ & $\begin{array}{l}87.50 \\
(0.96)\end{array}$ \\
\hline & 10 & $\begin{array}{r}1734.0 \\
(3.6)\end{array}$ & $\begin{array}{r}78.62 \\
(4.26)\end{array}$ & $23525.4(204.4)$ & $\begin{array}{r}75.59 \\
(1.40)\end{array}$ \\
\hline \multirow{2}{*}{ P9 } & 2 & $\begin{array}{r}1781.0 \\
(52.9)\end{array}$ & $\begin{array}{l}94.19 \\
(1.33)\end{array}$ & $\begin{array}{r}24917.2 \\
(1633.7)\end{array}$ & $\begin{array}{l}76.22 \\
(5.67)\end{array}$ \\
\hline & 10 & 1811.1 & 94.16 & 28114.9 & 72.67 \\
\hline \multirow{3}{*}{ P5 } & 2 & 1249.0 & 92.52 & 14691.5 & 81.57 \\
\hline & & $\begin{array}{r}(70.9) \\
2036.0\end{array}$ & $\begin{array}{l}(2.07) \\
83.66\end{array}$ & $\begin{array}{r}(972.6) \\
20012.7\end{array}$ & $\begin{array}{l}(5.12) \\
72.96\end{array}$ \\
\hline & 10 & $(170.93)$ & $(1.69)$ & $(2788.6)$ & $(6.12)$ \\
\hline
\end{tabular}

( ) parentheses represent the standard deviation.

When it comes to the effect of thermal concentration of the bioprocessed samples, a slight antioxidant decrease was observed for both concentrated fruit extracts. This could be caused by partial thermal-induced degradation of highly polymerized phenolics, known to be potent antioxidants (Cruz et al., 2001), which would lead to a little decrease of the antioxidant capacity of the concentrated extracts and the formation of simple detectable phenolics, which would also contribute to the extra TPC increase observed (Randhir et al., 2008).

\section{Amylase Inhibitory Activity}

All extracts showed some level of alpha-amylase inhibition, but a remarkable complete amylase inhibition was observed during the early stages for the G9 and P9 treatments (Table 2). It is worth noting that P9 concentrated and non-concentrated extracts had different levels of TPC after 2 days of growth, but similar anti-amylase activities. Similarly, G9 extracts after 2 days presented similar antioxidant activities, but only concentrated samples showed high amylase inhibition. In addition, during late stages of SSB (10d), G9 extracts showed similar inhibitory activity, despite their differences in TPC content. A clear dose-dependent relationship between TPC and alpha-amylase activity was not observed either, which means that concentrated samples do not exhibit an evident tendency of higher enzymatic inhibition.
Table 2: Alpha-amylase inhibition results for guava (G9, G5) and pineapple (P9, P5) concentrated and non-concentrated phenolic extracts after 2 and 10 days of growth.

\begin{tabular}{|c|c|c|c|}
\hline & \multicolumn{3}{|c|}{ Alpha-amylase inhibitory activity, \% } \\
\hline \multirow{2}{*}{ Treatment } & Days & $\begin{array}{c}\text { Non-concentrated } \\
\text { (NC) }\end{array}$ & $\begin{array}{c}\text { Concentrated } \\
\text { (C) }\end{array}$ \\
\hline \multirow{2}{*}{ G9 } & 2 & $41.72(0.39)$ & $100.00(0.00)$ \\
& 10 & $46.51(7.42)$ & $46.43(3.37)$ \\
\hline \multirow{2}{*}{ G5 } & 2 & $23.06(7.22)$ & $15.18(2.10)$ \\
& 10 & $36.43(5.37)$ & $13.69(2.53)$ \\
\hline \multirow{2}{*}{ P9 } & 2 & $100.00(0.00)$ & $100.00(0.00)$ \\
& 10 & $41.48(13.26)$ & $71.43(20.45)$ \\
\hline \multirow{2}{*}{ P5 } & 2 & $20.28(4.83)$ & $23.81(3.52)$ \\
& 10 & $30.69(0.83)$ & $10.91(3.05)$ \\
\hline
\end{tabular}

( ) parentheses represent the standard deviation.

All these experimental evidences suggest that amylase inhibitory activity is not directly linked to antioxidant activity or TPC, but rather perhaps to the presence of specific phenolic compounds or their modified forms. This behavior was also observed by Apostolidis et al. (2007), who affirm that the quality and the synergy of phytochemicals may be more relevant to enzyme inhibition than the TPC itself. Cheplik et al. (2010) also observed the same pattern for the alpha-amylase inhibition of strawberry extracts. They suggest that the enzymatic inhibition is independent of the antioxidant activity for specific cultivars. It is also possible that non-phenolic compounds might play an important role in inhibiting the activity of alphaamylase. 
For G5 samples, the concentration seems to decrease their functionality, as concentrated samples showed lower inhibitory activity when compared to non-concentrated ones. This may indicate that modification of phenolics or denaturation of phenolic-associated proteins contribute to a lower amylase inhibition.

Amylase inhibitors are also known to be starch blockers because they are able to prevent dietary starch from being absorbed by the body. Starch is a complex carbohydrate that needs to be first broken down by digestive enzymes such as amylase and other secondary enzymes in order to be absorbed. McCue and Shetty (2004) showed that phenolics have the potential to contribute to the management of type 2 diabetes by mediating amylase inhibition. Randhir and Shetty (2007) observed that extracts obtained during intermediate stages of solid state bioprocessing of mung beans (Vigna radiata) by $R$. oligosporus present high alpha-amylase inhibitory activity, with values ranging from $60 \%$ to $80 \%$ inhibition. The authors believe that the mechanism of glycolytic activity inhibition of alpha-amylase may occur through direct blockage of the active site or at several sub-sites of the enzyme.

Rohn et al. (2002) showed that plant phenolic substances react with proteins/enzymes, influencing their physicochemical properties and their in vitro enzymatic activity. Specifically for alpha-amylase, the authors affirm that the anti-enzyme activity depends on the concentration and on the number and position of the hydroxyl groups of the phenolic compounds.

\section{CONCLUSIONS}

The relationship between TPC, the free radical scavenging activity measured by the DPPH method and the alpha-amylase inhibitory activity of the phenolic-enriched fruit extracts obtained by SSB using the food-grade fungus Rhizopus oligosporus was investigated. Enzyme inhibition was observed for guava and pineapple extracts, concentrated or not, with values ranging from $10.19 \%$ to $100 \%$ (complete inhibition). No evidence of positive correlation was found between TPC and the free radical scavenging activity. The results do not show a clear dose-dependent relationship between TPC and alpha-amylase activity. It is suggested that amylase inhibitory activity is not directly linked to the free radical scavenging activity or TPC, but rather perhaps to the structure of the specific compounds, phenolics or not, or their modified forms.
Solid state fermentation (SSF) using food grade fungi could provide non-expensive strategies for producing biologically active products and enhance the value of fruit residues by providing a source of healthrelevant compounds. Although further investigation is needed to explore their potential therapeutic effects on postprandial glycemic response, it was shown that these bioprocessed tropical fruit extracts are able to modulate the enzymatic breakdown of carbohydrates by inhibiting in vitro alpha-amylase. Additional studies of the economical viability of the proposed process should be carried out.

\section{REFERENCES}

Aguilera-Carbo, A., Hernández, J., Augur, C., PradoBarragan, L., Favela-Torres, E. and Aguilar, C., Ellagic acid production from biodegradation of creosote bush ellagitannins by Aspergillus niger in solid state culture. Food and Bioprocess Technology, 2, no. 2, p. 208-212 (2009).

Apostolidis, E., Kwon, Y. and Shetty, K., Inhibitory potential of herb, fruit and fungal-enriched cheese against key enzymes linked to type 2 diabetes and hypertension. Innovative Science Emerging Technology, 8, no.1, p. 46-54 (2007).

Bocco, A., Cuvelier, M., Richard, H. and Berset, C., Antioxidant activity and phenolic composition of citrus peel and seed extracts. Journal Agricultural and Food Chemistry, 46, no. 6, p. 2123-2129 (1998).

Cheplik, S., Kwon, Y., Bhowmik, P. and Shetty, K., Phenolic-linked variation in strawberry cultivars for potential dietary management of hyperglycemia and related complications of hypertension. Bioresource Technology 101, no.1, p. 404-413 (2010).

Correia, R. T., McCue, P., Magalhães, M. M., Macêdo, G. and Shetty, K., Production of phenolic antioxidants by the solid-state bioconversion of pineapple waste mixed with soy flour using Rhizopus oligosporus. Process. Biochemistry, 39, no. 12, p. 2167-2172 (2004).

Cruz, J. M., Dominguez, J. M., Dominguez, H. and Parajo, J. C., Antioxidant and antimicrobial effects of extracts from hydrolysates of lignocellulosic materials. Journal Agricultural Food Chemistry, 49, no. 5, p. 2459-2464 (2001).

FAOSTAT, Food and Agriculture Organization of the United Nations Database. Available at www.faostat.fao.org. (Accessed in November 2010).

Hounsome, N., Hounsome, B., Tomos, D. and Edward-Jones, G., Plant metabolites and nutritional 
quality of vegetables. Journal of Food Science, 73, no. 4, p. R48-R65 (2008).

Kaur, C. and Kapoor, H., Antioxidants in fruits and vegetables - the millennium's health, International. Journal Food Science Technology, 36, no. 7, p. 703-725 (2001).

Kim, Y., Jeong, Y., Wang, M., Lee, W. and Rhee, H., Inhibitory effect of pine extracts on $\alpha$ glucosidase activity and postprandial hyperglycemia. Nutrition, 21, no. 6, p. 756-761 (2005).

Kwon, Y., Vattem, D. and Shetty, K., Clonal herbs of Laminaceae species against diabetes and hypertension. Asia Pacific Journal Clinical Nutrition, 15, no. 1, p. 107-118 (2006).

Kwon, Y., Apostolidis, E. and Shetty, K., Inhibitory potential of wine and tea against $\alpha$-amylase and $\alpha$-glucosidase for management of hyperglycemia linked to type 2 diabetes. Journal of Food Biochemistry, 32, no. 1, p. 15-31 (2008).

Lunceford, N. and Gugliucci, A., Ilex paraguariensis extracts inhibit AGE formation more efficiently than green tea. Fitoterapia, 76, no. 5, p. 419-427 (2005).

Mantovani, J., Correa, M., Cruz, M., Ferreira, M., Natale, W., Uso como fertilizante do resíduo de processamento de goiabas. Revista Brasileira de Fruticultura, 26, no. 2, p. 339-342 (2004).

McCue, P. and Shetty, K., A model for the involvement of lignin degradation enzymes in phenolic antioxidant mobilization from whole soybean during solid-state bioprocessing by Lentinus edodes. Process Biochemistry, 40, no. 34, p. 1143-1150 (2005).

McCue, P. and Shetty, K., Inhibitory effects of rosmarinic acid extracts on porcine pancreatic amylase in vitro. Asia Pacific Journal Clinical Nutrition, 13, no. 1, p. 101-106 (2004).

Morton, L., Caccetta, R., Puddey, I. and Croft, K., Chemistry and biological effects of dietary phenolic compounds: relevance to cardiovascular disease. Clinical Experimental Pharmacology Physiology, 27, no. 3, p. 152-159 (2000).

Naczk, M. and Shahidi, F., Phenolics in cereals, fruits and vegetables: occurrence, extraction and analysis. Journal of Pharmaceutical and Biomedical
Analysis, 41, no. 5, p. 1523-1542 (2006).

Randhir, R. and Shetty, K., Mung beans processed by solid-state bioconversion improves phenolic content and functionality relevant for diabetes and ulcer management. Innovative Science Emerging Technology, 8, no. 2, p. 197-204 (2007).

Randhir, R., Kwon, Y. and Shetty, K., Effect of thermal processing on phenolics antioxidant activity and health-relevant functionality of select grain sprouts and seedlings. Innovative Science Emerging Technology, 9, no. 3, p. 355-364 (2008).

Rogério, M., Borges, V., Neiva, J., Rodriguez, N. and Pimentel, J., Valor nutritivo de resíduo de abacaxi. 1. Consumo, digestibilidade, balances enérgetico e nitrogenados. Arquivo Brasileiro Medicina Veterinária Zootecnia, 59, no. 3, p. 773781 (2007).

Rohn, S., Rawel, M. and Kroll, J., Inhibitory effects of plant phenols on the activity of selected enzymes. Journal Agricultural Food Chemistry, 50, no. 12, p. 3566-3571 (2002).

Torres de Pinedo, A., Penalver, P. and Morales, J. C., Synthesis and evaluation of new phenolic-based antioxidants: Structure-activity relationship. Food Chemistry, 103, no. 1, p. 55-61 (2007).

Youdim, K. and Joseph, J., A possible emerging role of phytochemicals in improving age-related neurological dysfunctions: a multiplicity of effects. Free Radical Biology Medicine, 30, no. 6, p. 583-594 (2001).

Vattem, D. and Shetty, K., Solid-state production of phenolic antioxidants from cranberry pomace by Rhizopus oligosporus. Food Biotechnology, 16, no. 3, p. 189-210 (2002).

Zheng, W. and Wang, S. Y., Oxygen radical absorbing capacity of phenolics in blueberries, cranberries, chokeberries, and lingonberries. Journal Agricultural and Food Chemistry, 51, no.2, p. 502-509 (2003).

Zheng, Z. and Shetty, K., Solid state fermentation and value-added utilization of fruit and vegetable processing by-products. In: Wiley Encyclopedia of Food Science and Technology, 2nd Edition, Edited by F.J. Francis, Wiley Publishers, NY, p. 2165-2174 (1999). 